\title{
Opportunities in the Transforming Digital China
}

\author{
Emad Abou-Elgheit \\ International School of Management \\ Paris, France
}

\begin{abstract}
The paper aims to discover the most promising digital networking business opportunities in today's Chinese market, and how those new opportunities relate to the collective social networking culture rooted in Chinese consumers and businesses. The paper analyzes the enormous digital business environment in China for e-commerce, digital marketing, e-learning, consumer behavior, IT outsourcing, software development and innovation. The analysis discovers huge opportunities in China's digital social business that leverages the collaboration culture for both consumer and business audience. A classification to China's digital audience and current key global and domestic players in the digital market are provided. The market is still far from maturity with an enormous growth rate. Although local players dominate the market, new market entry depends primarily on new digital product features that leverage social interaction and networking. Current key players copy Western social networking business model style without taking advantage of China's collective culture. The market size is huge, however, concentrated in urban areas and for specific income levels. The research finds opportunities in consumer digital social shopping, mobile social shopping and professional digital networking. The paper provides implications and recommendations for international and domestic investors that include ideas for new digital products and market penetration strategies.
\end{abstract}

\section{Introduction}

How collective collaboration aspects rooted in the Chinese culture relate to the country's promising digital sector in the country? How businesses take advantage of those aspects to maximize the return of their local and foreign investments? To answer these two main research questions, one should understand the current digital and ICT market of China with its components of buyers and sellers, their behaviors and attitudes, size, structure, volume, and nature of competition. The paper focuses on digital and ICT sub-sectors that are affected by collaborative social networking. One also should understand the modern cooperation and social networking applications in today's business in China from both buyer and seller views. Finally, we need to understand how recent political and economic status and reforms affect that relation, or even drive it.

The word "Guanxi" in traditional Chinese describes how individuals in society form a social network where they can exchange favors and services between each other. This can be between two individuals with different social status where the person with a lower status can benefit from the other at a higher status. It also can be used to describe a similar network that involves many individuals or groups. As an example of an Eastern collective culture, Chinese entrepreneurs, consumers and even large State Owned Enterprises and private enterprises usually use collaborative strategies in their daily buying and selling transactions. With the increasingly-popular digital communication and collaboration tools, local and global businesses have great opportunities to take an advantage of those cultural aspects to build sustainable businesses and brands.

A tremendous growth has happened in ICT and digital sectors in China in the first decade of the $21^{\text {st }}$ century after the legitimatizing of private economic activities and ownerships, constitutional amendment at the second plenary session of the Ninth People's Congress allowed the move. Recent economic reforms and rapid GDP growth have raised Chinese people standard of living allowing for more consumption and higher spending patterns. The penetration of Western brands and openness to global cultures created a huge new market for consumer goods manufacturers. ICT products and services such as consumer electronics, e-commerce, enterprise information systems represent global shared needs among consumers worldwide with minimal localization or customization needs. China has also become more attractive to international operations and foreign expats and entrepreneurs. According to the Shanghai Daily, the number of foreigners living in main land China reached nearly 600,000 in the year 2010. This has created a new segment worth targeting with global and focused products and services. Enderle argued that recent economic growth in China in the last few years after the global recession in the year 2008 actually came from domestic market rather than the traditional export economy growth as illustrated in Figure 1. Accordingly, this would require a strategy change 
and a strong adaptation to Chinese consumer behavior and specific buying patterns.

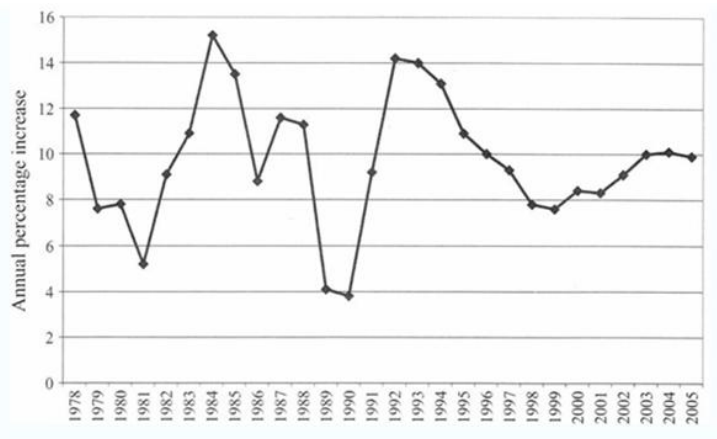

Figure 1. Annual GDP growth 1978-2005. Source. Naughrem, (2007)

China's currently represents the world's largest social media digital community with over 300 million active users who also are the most active users with more than $40 \%$ of their time is spent on social networking, blogs and micro blogs [1]. While they use similar behavior as the rest of the world's online users, the tools are currently different and fragmented. The big four of social media (Facebook, YouTube, Twitter, and LinkedIn) websites - except for LinkedIn - do not exist in China. Instead local and fragmented Chinese similar platforms do.

While the country has gone a long way in a record time to loosen its entry barriers and encourage local and global private investments, China's market is still considered to be challenging to develop as many regulations, internet censorship and protectionism practices still need to be addressed.

\section{Analysis}

As illustrated in Figure 2, the research qualitative analysis framework tackles the social collaborative business in China in terms of macro environment, characteristics and factors of integration for collective culture and digital business in China.

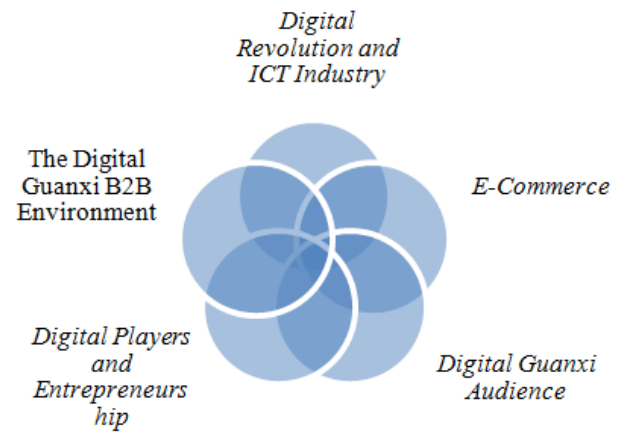

Figure 2. Analysis Framework
The objective is to find digital business sectors that are affected the most by social collaboration to determine most promising business lines for investors, global corporations and entrepreneurs interested in conducting digital business in China.

Analysis starts by understanding digital and ICT environments in China, and then moves to studying China's e-commerce sector, digital audience in terms of demographic, culture and behavior. Analyzing key digital market players in China and entrepreneurship in that area comes next. Finally, the analysis studies $\mathrm{B} 2 \mathrm{~B}$ digital business environment in terms of ICT outsourcing opportunities and collaborative B2B practices in China.

\subsection{Social Networking as a Cognitive Science}

Social networking in business depends on individual motives behind favors exchange. The cognitive science is the broad collective science for studying mind and intelligence, philosophy, psychology, artificial intelligence, neuroscience, linguistics, and anthropology. The core philosophy of cognitive science is that thinking process should be understood in relation to representational structures in the mind and computational procedures that operate on those structures. In other words, cognitive science claims that human minds use mental representations such as; logical propositions, rules, concepts, images, and analogies - approaches that are similar to computer and artificial intelligence - and operate on these structures. People do not make similar inferences to similar situations, and do not react or solve problems the same way. This is due to having different formal logic and different rules. Like computer programing languages, minds are mostly programmed to "if..." "then..." type of processing, where these conditions differ according to different past experiences, emotions, concepts, analogies, and intelligence levels [2].

\subsection{Social Networking for Brand Building}

According to Rowley, there is not an exact percentage number that can measure communications and networking contribution to brand building effectiveness, however being the heart and soul affecting brand building; it should exceed 50 percent. With the start of the digital age in late 1990s represented in internet and mobile communications, traditional concepts and approaches to build a brand has changed forever. Consumers now are more empowered than ever with almost full control over their brand experience. Consumers are no longer receivers to mass advertising, but became proactive in searching, selecting, comparing, and personalizing their buying process. The internet has also enabled the globalization of brands in less time having websites accessible from all over the globe. 
With the proper search engine optimization and cross-cultural websites, organizations now are able to reach their prospects anywhere in a cost-effective and efficient way.i Latest trends now in designing web user experience and building online brands are no longer emphasizing on having fixed attractive interfaces and contents for users to interact with, based on usability analysis and creative designers best judgment. The new approach now is building the base for usability, functionality, and contents rules and having users customize their own experience with drag-and-drop, simple and logical actions. Users can choose what type of contents to appear to them in their next visit, what size of text, what colors, screen resolution, videos and image quality, and even where these contents and web blocks are placed in their interface. In other words; users are building their own customized brand and brand experience. From a customer relationship management perspective, internet has enabled organizations to build their brands through collecting prospects and customer data in databases and segmenting these customers accurately and efficiently to target later with personalized email campaigns, focused messages and one-to-one marketing. With the rapidly-developed telecommunication and mobile services, marketers now have a new dimension to target their customers and build their brands; that new dimension is the location. Mobile advertising can now target customers according to their current location highlighting products and services nearby. Taking the public sector and governmental institutions as an example; governments worldwide started what is called Gov2.0, an approach that aims to allow citizens to engage and interact with their local government authorities about their requests, pain areas and needs over the social networks through the internet and mobile devices. Crowed Sourcing; is a new approach that empowers citizens to act as a source of information to report traffic incidents and weather conditions for other citizens to learn about in real-time. Government authorities buying such software solutions are keen to build their own government brands through integrating these new eservices with popular social networks and mobile applications. On the other hand, citizens receiving the actual services can also help software vendors in defining these e-services features before its actual launch through interacting with software vendors' social media channels.

Schultz argued that during the dot-com boom in the late 1990s, new digital brands did everything to build awareness by introducing efficient names, attractive web pages and graphics. The result was a great failure for many of them because they adopted traditional brand building techniques invented by consumer goods giants and applied it online. Where packaged-goods companies owned the full customer experience through packaging, distribution and advertising, online consumers owned a great deal of brand experience through their control over information presented online. In the global financial crises started in 2008, Google, for example, was able to build even greater brand awareness and increase sales substantially by attracting more online sellers to save expensive TV and printed advertising budgets and use Google AdWords, an application where online sellers bid on certain Google search keywords to appear in first search results. What brand owners also should be aware of is that economic downturns are a golden chance to test their brands' performance and true equity and make sure they are still relevant and value-adding to consumers. Strong brands that survive recessions proved to come out stronger than ever before. Marketers should also be careful not to introduce new brands or transform successful brands into generic ones due to short-term selling and marketing tactics that can conflict with the long-term strategies for their brands.

\subsection{Global Software Development Industry}

The estimated $\$ 2,351.1$ billion in the year 2010 global software development industry has an annual growth rate of 7.5 percent for the period spanning 2006-2010. The global market value is distributed between Americas (32.4 percent), Europe (26.4 percent), Asia (23.1 percent), and rest of the world (18.1 percent) [3]. Most popular destinations for outsourcing and exporting software services include; India, China, Egypt, and Eastern Europe. Because of the common development languages and ease of distribution, the industry can be considered one of the most globalized.

The industry is divided into two main categories; software services, and software products. The services category encompasses tailored software solutions that are made specifically for a specific customer need. It is usually popular with large enterprises that need a greater degree of customization of existing software platforms or infrastructure, as well as developing new applications from scratch to fulfill their business needs. Key competitive aspects are; efficient production processes, and customer support. Software products on the other hand are ready-made solutions that are designed for a common need and can be purchased and used directly by customers across the globe. Porter argues that in the product category, key competitive aspects are innovation management, marketing, and time to market. Packaged software industry is considered to be one of the most profitable global industries estimated by more than 35 margins in the year 2008 .

The industry is dominated by few global players including; IBM, Microsoft, Oracle, Google, Apple, Wipro, and Adobe. The global players are involved 
in both services and products category. They depend on many small and medium software vendors across the globe to subcontract, customize, and enhance their platforms and products for different global customer needs. Global key software giants have the upper hand in bargaining power in the global market due to their dominance in providing main development platforms that smaller suppliers use in their own development.

In smaller and focused software products, there is a low switching cost for buyers. However, for larger enterprise solutions, the cost of switching is extremely high due to a complex process of migrating all IT infrastructures to a new tool.

The industry is truly dynamic. New tools and technologies platforms and solutions emerge rapidly with an extremely short product lifecycle. Latest trends in the past few years have included Cloud Computing, a technology where users and businesses can access software applications through web browsing instead of installing on their own computers. This can significantly lower costs and enhance collaboration [4]. Tablets and mobile apps are also a huge growing market. Social applications are found in almost all software tools now enabling users to communicate with other users and peers.

\subsection{China Digital Revolution and ICT}

In such strategic sectors such as ICT infrastructure, software development and IT outsourcing, the image is a bit different from consumer products. Here, China can't do it all on its own yet, and still has to rely on Western expertise to grow this sector. Accordingly, the government has facilitated entry to many global Western corporations such as Microsoft, Apple, and IBM. Other global software vendors such as Dell and HP were keen to establish software outsourcing centers in China [5]. With the increasing entry facilitations, the most popular entry strategy for such corporation is still through collaborating with local partners, and government authorities [6]. In terms of China's ICT promising sector, computer hardware and electronics manufacturing are progressing strongly. Chinese software products, services, IT and outsourcing exports represent a growing industry worth \$23 billion in 2008 [7]. However, global quality concerns are yet to be overcome [8].

China Telecom established the first internet connection to the US in the year 1995. Shortly, it was available to more than half a million users in the year 1997, a number that expanded rapidly to reach 300 million users in the year 2009 [9], and 538 million users with a penetration rate of nearly 40 percent in 2012 [10]. China's ICT market grew by nearly 17 percent during the area between 2004 and 2009 [11].
China plans for launching an entirely new era in television entertainment. By 2015, Chinese television networks will provide only-digital broadcast. For marketers and businesses, this means high definition contents, numerous new channels, and more ondemand watching patters [12].

\subsection{China E-Commerce Market}

Unlike the US market for example, the Chinese e-commerce market is at its growth phase and didn't reach maturity yet which creates tremendous opportunities to penetrate. E-commerce adoption in China is only at 25 percent creating a large gap between Western developed markets as illustrated in Figure 3 [13]. In terms of quantity, the picture is different. Chinese online shoppers are expected to represent 44 percent of the total urban population by the year 2015, and are also expected to represent more than seven percent [14] of China's total retail value of currently Yuan 4.8 trillion. China's eshoppers currently spend $\$ 314$ billion, and are expected to surpass the US total value by 2015 . Growth rate of this market is as rapid as 39 percent annually in the years 2011 to 2012 [15]. The market yet seems to be monopolistic having the Amazon.com-like Taobao dominating the current market. Amazon, e-Bay, Alibaba and other global brand e-stores also represent a significant portion of total sales. Government sought to boost telecommunications capacity, escrow accounts eased payment concerns and firms took advantage of shipping costs about one-sixth of those in the US. Most of these e-commerce sites integrated basic social networking capabilities into their sites.

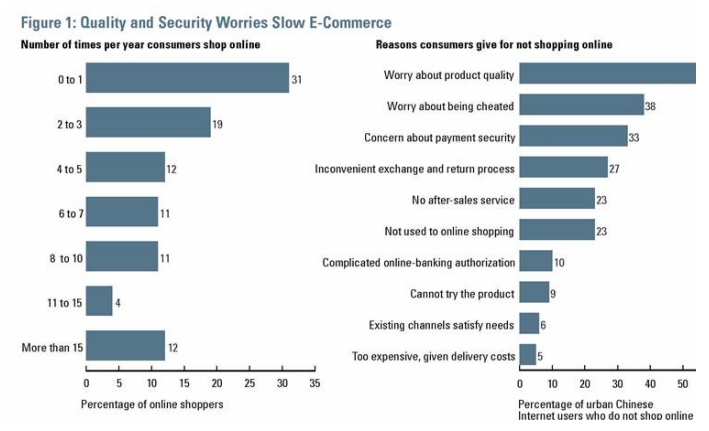

Figure 3. Quality and Security Worries Slow ECommerce

China's social e-commerce seems to have gone a long way in terms of maturity, perhaps even more than many Western online shopping websites in some areas. In the year 2007, B5M, a Shanghaibased social shopping search engine was launched. It offered millions of products with a shopping experience that is empowered by tons of user reviews, ratings, and expert advice. The privately- 
held company owning B5M portal is clearly taking advantage of the Chinese government commitment to ease e-commerce and foreign investments in light of the reform [16]. The strong market entry by the Chinese B5M didn't stop the world's leader from developing its Chinese footprints. Recently in 2012, the world's largest integrated digital marketing company, Xaxis launched its operation in China. The company provides local and global advertisers with comprehensive integration of digital television, mobile, and social networking marketing tools based on data driven from tracking users' online behavior [17].

Chinese government transformational efforts are clearly paying off. Free transfer of labor and technology across national and international borders [18] has certainly enabled local social media companies to copy the Western product innovation and introduce it with a Chinese flavor that appeals to local tastes and culture, and most importantly, abide with local regulations.

\subsection{China Digital Guanxi Audience}

With the introduction of the one child policy, and the rising standards of living since political and economic reforms, China's today digital consumers are unique in terms of characteristics and demographic. The global digital boom at the end of the last century has been witnessed by today's middle aged audience, not only the young. This means that China is moving towards an aging population like the developed world. This also means that products and services offered online should not only attract young high-tech geeks, but also middle aged and senior citizens. A study conducted by China Business Review calls the current middle aged audience in China who witnessed the reform from its beginning (26-35 years old), the Reform Beneficiaries, and calls the younger audience born at the rising economy the Little Emperors (14-24 years old). Reform beneficiaries are more accepting to opinion leaders and resilient information, while little emperors demand more details and abundance of information. The latter category also has less trust in opinion leaders.

Another study made by McKinsey \& Company in 2011 - illustrated in Figure 4 classifies China's digital audience into seven categories based on their usage time, sophistication and mediums used. The heavy users of social networking sites are low-tier online gamers (nine percent), heavy digital users of young early adaptors to new tools and gadgets (six percent), mobile users who listen to music and read online (eight percent). 18 percent of China's digital audience use internet for stock trade, that huge audience is usually middle-aged males and entrepreneurs. Another 17 percent are middle aged information searchers on specific business subjects
[19]. Many Chinese social media users have multiple accounts, and usually underestimate expert advice of opinion leaders due to being skeptical of governmental authorities monitoring. They rather put greater trust to peer reviews and user ratings [20]. Companies marketing on social media usually use centralized official writing champions in their feeds. Local social media platforms are fragmented and highly region-specific. A situation that isn't strange knowing the recent political and economic reforms in China highly empowered local governments and municipalities for more autonomy over their economic development.

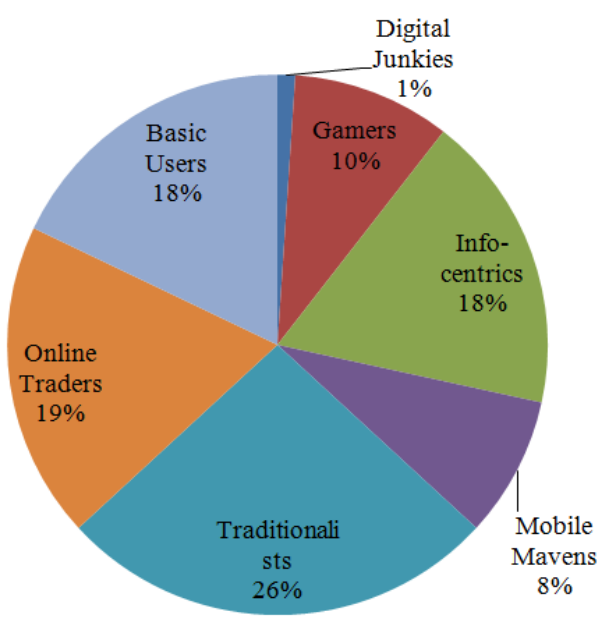

Figure 4. China's internet users classification. Source. (McKinsey \& Company, 2011)

Brand builders using social media in China are often dragged into the mistake of building a one-way communication bombarding fans with all brand information, while what actually matters to users is responding to enquiries in a time efficient and consistent manners. Converting brand fans into advocates involves using popular Chinese language in conversations. Targeting clusters of friends and families in local community is another key factor for success (Chan J. Social Media Report: Popular platforms the key to gaining brand fans in China. Campaign Asia-Pacific, 2012). Chinese online shoppers still worry about product quality, price manipulation, and payment security, concerns that can hinder the saturation of that promising market.

\subsection{China Key Digital Players}

Examples of leading Chinese social media platforms include Twitter-like micro blogging sites such as Sina Weibo, Renren, and KaixinOOl. For multimedia discussions and sharing, there is Douban. For mobile social networking and chatting, there is Wechat (Mashable). For Facebook-like media sharing and chatting communities, there is QQ, and Qzone (FortuneMagazine). Analyzing the business 
model for these platforms clearly indicates no product innovation or new groundbreaking software ideas. They provide similar features and workflow as Western pioneers such as Twitter and Facebook. However, it is worth mentioning that they are unique in how they are tailored for Chinese consumers in terms of contents and look and feel. In terms of usage and number of accounts, any of these platforms can be considered a strong rival for Western similar platforms. Regarding Chinese audience, we talk hundreds of million users for platforms that do not exist except in China, a fact that should create easier market penetration and reduction to message clutter. In the same way it isolates Chinese digital audience from the rest of the world.

It is crucial to notice that most - if not all - social media platforms in China are not State Owned Enterprises. They are rather private companies established by Chinese entrepreneurs. This indicates a significant trend for private high-tech investments in China since almost half of China's GDP now comes from private enterprises. Talking about entrepreneurs, and from which the above analysis confirms, most of these enterprises are based in Chinese urban and developed areas such as Beijing and Shanghai. The market fragmentation corresponds with great opportunities for times of global uncertainty and financial crises. The dramatic growth rate of number of entrepreneurs and private business owners in China promises huge future opportunities for Chinese and foreign investors more thriving possibilities in the world's next strongest economy.

\subsection{China Digital B2B Environment In}

Unlike Western corporations, Chinese enterprises tend to adapt a collaborative success business model. Instead of competing aggressively and aim to kill competition, they aim instead to create mutual success in domestic and international markets. As a solid integral part of culture, business professionals and entrepreneurs depend highly on social networking in making business. A study conducted on a range of business owners in Beijing and a rural city in Western China confirms this argument. The study found the size of a social network between business owners, as well as the size of a network between business and government officials are strongly related to business success and growth of these organizations. The same paper suggests that Chinese businesses tend to use Guanxi in business not only because it is embedded in their culture, but also because China's business environment might lack formal or structured institutions to facilitate networking and communications. The recent reform attempts by the Chinese government have empowered local governments with more autonomy, which means that these business networks are highly-fragmented and local.

The main question here is how these social networks are formed? And what are the mediums of communication among business individuals to establish and maintain relationships? What happened across the Chinese history is that Guanxi communication was established through face-to-face meetings, social gathering, gift giving, and telephone. But in today's world, are these communication mediums still the most effective? And did any other mediums emerge? The answer is that traditional approaches in building a business Guanxi can be digitalized in full or in part. Selecting mutual potential contacts and finding mutual benefits can be conducted using online professional networking sites and CRM applications. Other steps also can be empowered by such tools.

Vanhonacker suggests a four-step approach in building an effective business Guanxi; targeting, scouting, signaling, and packaging. The process starts by identifying target connections that match your strategic business objectives, and then start finding mutual points of interest with them. The third step is to start signaling your selected network through a social event or invitation. Finally, a proper packaging of request can be conducted in an ethical manner and a good image.

Top professional social networking platforms in China include; Tianji, WealinK, Hengzhi, Jingwei, and Ushi. The market is oligopolistic with Tianji and WeaLinK accounting for more than five million users each, while the rest are fewer than one million each [29]. Tianji and Ushi are available in English. LinkedIn, the global leader professional network is available as well in China, but with a minimal market share. Again, user experience in these sites represents a Chinese copy of their Western rivals with no significant difference or special innovative features.

\subsection{Global E-Learning}

Rodrigues and Zhou argue that the increasing penetration of social networking applications have extended to reach almost all digital applications. Many LMS makers added social networking integration features to their software. It's been proved that social sharing; collaboration and integration of learning contents and media between users over social networks improve the overall learner experience. Sebastianelli and Tamimi also argue that in higher education, professor-student interaction features are found to be the most useful. Features promoting student-student interaction are the least useful, and discussion forums are of limited value in learning quantitative business courses content such as statistics. In the same field, a study 
made on Moodle LMS showed that users care the most in an LMS for quality and functionality of the learning platform. Braccini and D'Atri say the quality and efficiency users get the information and reach their research objectives easily are the key factors that affect their perception in evaluating a leaning platform. This includes; the platform performance in terms of speed of page load, structure and adaptation to individual learning style of learning materials, and ease of navigation. Usability and application ease of use is found to be the most important factor in evaluating a learning platform. The use of multimedia in tutor's notes is also found effective.

A huge revolution in assessment technologies and software applications helps e-learning process to have successful implementation. Technology in simple terms detects user's interaction and level of feedback, materials read, questions answered to generate unique contents for that user's own level and skills. This helps providing a personalized learning experience and promotes autonomy. Assessments tools following that approach can adapt to user's answers to generate next questions level of difficulty based on historical answers resulting in a more effective assessment experience. Emerging software tools such as E-Test can automatically-track learner's performance during course interactions and provide real-time feedback. Other variety of assessment approaches are being used for diverse purposes. These approaches include; as adaptive delivery of content, personalized learning materials, dynamic feedback, cognitive diagnosis, score reporting, and course placement.

Software makers usually increase the number of features in a learning platform without a careful consideration of which among those features is really important to users. Ching-Hsue suggest an automated mechanism that tracks usage of learning platform features to spot the frequently-used features from the least used to be removed in order to enhance and simplify the overall platform usability and ease of use.

\subsection{China's Other ICT Sectors}

No need to argue the substantial progress that China has achieved in electronics and electric household industries. The country has become the backyard factory for almost all global electronics manufacturers. This has been achieved clearly through leveraging China's comparative advantage in efficiency and low labor cost. However, China did not witness similar or even near progression in innovating new products and services. While few Chinese electronics brands such as Hair are starting to penetrate Western markets, product quality is still a major concern for these types of buyers. China's current position holding all major electronics manufacturing of global brands represent a strategic advantage to China controlling global product prices. However, it also distracts China from investing into new product research and development and sustaining a long-term competitiveness in that sector.

\section{Conclusions}

China's digital market entry should be looked at as an opportunity rather than a challenge. The market size and attractiveness should overcome its remaining entry barriers. The Chinese government allocates greater support and facilitation to that sector even more than other sectors. However, these facilitations are mostly directed to Chinese entrepreneurs rather than international investors. In other ICT sectors that require more technical knowledge and innovation, entry for global corporations is easier. These sectors include; software development, electronics manufacturing and IT outsourcing. The government also should invest in building the necessary IT infrastructure in rural areas to create new domestic demand for digital products and services.

The empowerment offered to local and regional governments and municipalities with the reforms have affected China's digital business and audience to be more fragmented and highly-local. While this provides consumers with more tailored products and services, it also hinders the nation-wide integration of knowledge and information.

Digital Guanxi is more mature in China than many people think. It operates within a sort of an isolated space from the rest of world, yet operates in the same way as in the West. Chinese social networking sites targeting consumers and professionals operate within an oligopolistic environment in most cases. Smaller players are highly fragmented among local regions and interests. For business networking, the picture is not much different, while the market is less monopolistic than consumer networking; it still lacks features that leverage the Chinese Guanxi properly in doing business and professional networking. It is worth mentioning that the vast majority of that audience is from urban areas with high internet penetration and standards of living. Not that the later audience is considered to be small in terms of size, but the real penetration to that market can come from creating new users from rural areas with low standards of living. Professional social networking in terms of size is far less mature than consumer ones. There is a great opportunity for growth in that sector, especially with fragmented existing competition.

Consumer social e-commerce sector is extremely promising in China with a high growth rate and long way till saturation. Collaborative social shopping is happening, yet still with no tangible difference from its Western rivals in terms of leveraging social activities in buyer's decision 
making process. Concerns for product quality and payment security are hindering the advance and growth of that sector among Chinese consumers. Current key player are not conducting proper consumer segmentation that leads to personalized products, contents and user experience based on demographics and psychographics of consumers. China's toady young online shoppers require greater degrees of personalization and user experience. The one child policy and the rising standards of living created many little emperor shoppers who expect nothing but the best shopping experience and content personalization. Elder Chinese shoppers, who are expected to increase due to the move towards an aging society require sellers to rethink their product mix and offer tailored and customized new products for that aging population.

Digital sectors that are most promising for investors should be looked at from two angles; local investors, and international investors. For domestic investors, fields of collaborative social consumer shopping is the most promising, especially mobile commerce as the market is yet way behind saturation with a low e-commerce penetration, especially in rural areas. Despite the current monopolistic environment in that sector by Taobao, new entrants can create a Blue Ocean strategy offering extra collaborative shopping experience features and operations in rural areas. Another promising sector is within the professional social networking sites. With an oligopolistic current competitive environment, there are chances for new entrants to dominate the market. Again, new innovative features that leverage social networking cultural practices are the key to success.

For international investors and global corporations, the area of consumer product digital shopping, internet and e-commerce are still very challenging to penetrate. Examples of unpleasant entry attempts include; Google, Yahoo, LinkedIn, Facebook, and others. This is primarily due to Chinese government internet censorship regulations and protectionism for local competitors. Successful entry would highly depend on establishing solid relationships with local partners and government officials. Software development and IT outsourcing are very promising sectors for global corporations. More control and involvement over quality is a major concern though.

Electronics new product manufacturing is not only an excellent green field to invest in, but great opportunities exist in leading the global market of new product development. In that sector, it is challenging for foreign investors to start alone. Instead, a joint venture or other collaborative shapes would be most suitable. Foreign expertise in electronics product innovation combined with the proper Chinese state-owned and private enterprises would create a good match to start a nation-wide initiative for China to start its footsteps on product innovation path.

\section{Recommendations}

Great untapped potentials for China's digital business can flourish. From a broader perspective, the Chinese government should move on with the successful economic and political reform. Tough decisions have to be made. More open economy, encouragement for local and international private sectors, and free trade practices should happen. In order for China to lead the world economy, it has to show more openness to the outside world and to integrate into the global economic culture. Chinese government should also take the initiative to build a new economy that is based on new product innovation rather than the current export and product assembly economy. Government authorities responsible for foreign and domestic investments should open interactive digital communication channels through web social media in Chinese and English where investors can ask questions and provide feedback regarding their investments process. This can be automated by establishing a knowledge management system with answers database for frequent questions and inquiries and resolutions to previous problems.

China can lead the world's digital collaborative business leveraging its unique Guanxi which is embedded in its people's culture. For consumer business, social shopping experience should have innovative features that take the world's consumer ebusiness to the next level. Chinese software developers should design smart web applications that can detect user preferences automatically based on their usage history, location, demographic and spending patterns. Clutter-free and personalized contents should be offered to Chinese web surfers. On top of the semantic personalized web, social networking should move beyond basic integration with shopping websites allowing people to share and comment. For example; candid and verified user ratings for products should promote product prices to be sold at a premium. Why? Because Chinese people would trust to a high extend their peers' reviews and opinions regarding products offered. User ratings should not just be for product quality, but also for convenience of buying, customer service, and other brand-related aspects. Affiliate online marketing tools should be leveraged allowing local small-scale sellers to collaborate into having a shared virtual stock of similar products. Integrating inventory databases for local small sellers should enable them to serve a wider audience and even compete on a regional level. Highly-localized websites should be built to target each rural community carrying a local flavor. For larger organizations, this doesn't have to be through creating separate companies. Instead, one 
company can create multiple user interfaces and online stores that highly target each small community, while their back end has the same database and staff. Promotions should be highlybased on user rating and previous experience. For example; displaying user rating with product price and pictures at the online shop interface should be as equal if not greater than them.

Product quality concerns should be addressed by communicating different product mix at different prices clearly to consumers. For example; local governments can create standard product grading scale where each product is categorized under. In this case, consumers would know what they are bargaining for and compare prices effectively. Brand communities should be a key initiative for marketers to recruit local opinion leaders and associate them with their brands. Images and advertising with local opinion leaders should be highly-visible in image, voice, and video testimonials and ads. Selecting these local opinion leaders should be done with great care not to cause skepticism by buyers.

Special products should be customized for local groups, friends, unions, and even families. For example; a certain family or school colleagues can request unique clothing or accessory designs that are customized for them. Buyers themselves can use digital platforms to customize T-shirts, mugs, accessories, and other items and order them in quantity for their friends and family as a collective social purchase. Another promotional tool can be by using social networking of buyers to get more discounts on their purchases. For example; the more transactions comes through a recommendation or a referral from a buyer to his or her local community, the more price discount he or she can get in future purchases.

Mobile and tablet devices are far from being utilized to leverage the Chinese Guanxi. Locationbased advertising integrated with social networking can be used to track and conduct local social gathering of friends and family. Not only receiving a happy hour ad at a nearby place, but also recommending the place where friends and family are gathered. Same goes for music, magazines, and books streaming and downloads on tablets and mobiles. Digital applications should not promote most viewed and downloaded media only, but most viewed and downloaded by friends, coworkers and family.

Digital on-demand television should be integrated with other digital communication tools such as the internet and mobile. Viewers can review, rate and vote over different broadcast channels. Viewers can use social media in exchanging views and even interacting with broadcasts through phone calls, online and mobile.

For professional social networks, the key success factor for domestic investors is to provide unique features that can leverage Guanxi building. Gift giving and exchange can also be digitalized. Business professionals can use web applications to exchange gifts with customized features and wrappings such as e-books, videos or music. Coworker recommendations and endorsements should be highly-integrated with professional profiles leveraging positive word-of-mouth. Knowledge management for business experiences can be shared among local community professionals such as best practices and lessons learned in business. Virtual professional events, webinars, and online meetings should be conducted, especially in rural areas to overcome long distance challenges. Digital business magazines should be highly targeted with personalized contents based on business sector, location and social networking.

In terms of the digital product mix, young Chinese high-tech addicts should be targeted with highly-integrated digital products that involve their own social network. Western flavor products can be appreciated. Status tools such as location check-in, new buys, gaming, and multimedia usage should be shared easily and integrated with their digital experience. Elder users can be targeted by a more sophisticated communication message ensuring data security, privacy and reliability. Information filtering and rating features are key features to be available in their digital products. Chinese product innovation should invent new digital products for Chinese senior citizens. Dedicated digital magazines, on-demand television, and targeted mobile ads can be used. Low-tier consumers in rural areas should be addressed with tailored digital products and services as they represent a huge untapped market to be developed. With the increasing number of international expats and foreigners living today in China, they themselves represent a new target segments for digital product makers. These products can involve translation, language aids, links to expat communities, and facilitated communication to home countries.

Mobile and tablet apps are now considered the new global trend. Apps designed specially to build social and professional Guanxi should emerge by software innovators. These apps should integrate with users' address books, online browsing behavior and references, as well as with organizations' ERP, and CRM platforms. They should also be highlypersonalized with social networking tools.

For software and IT outsourcing business, international corporations should continue to invest in China in that sector. However, they need to integrate Chinese teams with their global processes and project management methodologies to maintain quality and control. Dedicated integration functions should emerge from multinationals to recruit and integrate their Chinese offshore teams into their global business process. Specific objectives and 
metrics for that integration should be implemented. Multinationals should integrate gradually Chinese teams. They can conduct pilot projects and learn from mistakes before engaging offshore teams in key strategic projects. On-site visits and trainings should be conducted. Face-to-face communication should happen.

For international digital investors aiming to develop new digital market in China, like any other place, content is the key to success. Developing the right content, tagging, classifying, and disseminating it through intranet, extranet, internet, mobile, and digital broadcasting can lead to success. Extensive knowledge about Chinese culture and domestic societal fabric is an important consideration. Investors must be candid to learn about culture, rules and regulations and follow it carefully in order to be successful in China. While these regulations can seem complicated and different from Western economic and political norms, the government is moving slowly towards more facilitation for international investors. Building the right network with business, individual and government is the key factor for the success of new investments. The more capital you intend to start with, the more your business can conflict with domestic competition or regulations, the more powerful, complex and highranked your Guanxi should be.

\section{References}

[1] Chiu C., Ip C., Silverman A. Understanding social media in China. Mckinsey Quarterly [serial on the Internet]. (2012, June), [cited May 29, 2013]; (2): 78-81. Available from: Business Source Complete.

[2] Thagard, P., Cognitive Science. The Stanford Encyclopedia of Philosophy. (Fall 2012 Edition). Retrieved from

http://plato.stanford.edu/archives/fall2012/entries/cognitive -science/.

[3] Software \& Services Industry Profile: Global. (2011). Software \& Services Industry Profile: Global, 1.

[4] Aljabre, A., (2012). Cloud Computing for Increased Business Value. International Journal Of Business \& Social Science, 3(1), 234-239.

[5] HP, Dell to Establish Software Outsourcing Centers in China. (2009). EmergingMarketsNOW, 11.

[6] T. Ambler et al, "Creating harmony", in Doing Business in China, Taylor \& Francis Ltd / Books, 2000, pp. 111-126.

[7] China's Software and IT Outsourcing Market Reaches \$23Bn in 2008. Emergingmarketsnow [serial on the Internet]. (2009, June 17), [cited May 29, 2013]; 1. Available from: Business Source Complete.
[8] PR, N. (2012, June 13). Release of the 2011 (the 8th) China Software Export and Service Outsourcing Ranking List. PR Newswire US.

[9] TimeToast. (2012, November 21). The Internet \& China - A History. [Online]. Available: http://www.timetoast.com/timelines/44445

[10] PCWorld. (2012, November 21). China's Internet Population Reaches 538 Million. [Online]. Available: http://www.pcworld.com/article/259482/chinas_internet_p opulation_reaches_538_million.html

[11] Convergence assists ICT market growth (2005, November 25). Beijing: China Internet Information Center. http://search.proquest.com/docview/ 190629484 ?accountid=149115

[12] George, G., (2008, Sep 18). China's digital revolution. http://search.proquest.com/docview/ 206277431 ?accountid $=149115$

[13] Meyer, Michael, David C. Michael, and Christoph Nettesheim. "Reaching China's Digital Consumers." China Business Review 36, no. 1 (January 2009): 24-27. Business Source Complete, EBSCOhost (accessed May 29, 2013).

[14] China E-Commerce Seen Spiking, WWD: Women's Wear Daily [serial on the Internet]. (2011, Nov 22), [cited May 29, 2013]; 202(108): 2-1. Available from: Business Source Complete.

[15] Statista, (2012, November 25). Annual growth rate of China's e-commerce market from 2009 to 2015. http://www.statista.com/statistics/220265/chinas-ecommerce-annual-growth-rate/

[16] B5M. (2). Chinese Social Shopping Search Engine B5M Secures \$7.1 Million Series A Financing Round Led by Oak Investment Partners and Giosis Holdings. Business Wire (English).

[17] Xaxis launches in china; brings data-driven audience buying to country's digital media market. (2012, Oct 10). Business Wire. http://search.proquest.com/docview/ 1095508957?accountid=149115

[18] Chow G. GLOBALIZATION AND CHINA'S ECONOMIC DEVELOPMENT. Pacific Economic Review [serial on the Internet]. (2006, Oct), [cited May 29, 2013]; 11(3): 271-285. Available from: Business Source Complete.

[19] Lin, D. et al., (2011). Understanding China's Digital Consumers. McKinsey \& Company. Retrieved from http://www.mckinseychina.com/2011/02/23/understanding -chinas-digital-consumers/

[20] Magni, M \& Atsmon , Y. (2012, December 5). Segmenting China's Social Media Market. HBR Blog Network, http://blogs.hbr.org/cs/2012/08/

segmenting_chinas_social_media.html 